\title{
REMOVAL OF FLUORIDE FROM WATER AND WASTE WATER
}

\author{
SHRIVASTAV A* AND BHATT P \\ Department of Microbiology, Parul Institute of Applied Sciences, Parul University, \\ Vadodara, Gujarat, India
}

*Corresponding Author: Dr. Anupama S: E Mail Id: anupama.shrivastav82045@paruluniversity.ac.in Received $13^{\text {th }}$ April 2021; Revised $11^{\text {th }}$ May 2021; Accepted $19^{\text {th }}$ June 2021; Available online $1^{\text {st }}$ Feb. 2022 https://doi.org/10.31032/IJBPAS/2022/11.2.5853

\begin{abstract}
Fluoride is a chemical element which is present in environment. Standard fluoride content in drinkable water not be exceed than $1.5 \mathrm{mg} \mathrm{F} / \mathrm{L}$ according to the World Health Organization (WHO).Excess amount of fluoride ingestion leads health issues. It is compulsory to remove extra amount of fluoride. For this reason, many method have been established for remove fluoride from water and waste water such as ion exchange, precipitation, Donnan dialysis \& electro dialysis, adsorption, membrane process like reverse osmosis \& nano filtration, coagulation etc. kalinite, bentonite, charfines, nirmali seed \& lignite are the low cost materials used for removal of fluoride from water by batch adsorption.
\end{abstract}

Keywords: fluoride, removal, water and wastewater, adsorption, membrane technology INTRODUCTION

Toward the global water scarcity problem, recycling and waste water treatments are the most effective solution. To meet the drinking and effluent standards of water, we must need to remove various organic and inorganic recalcitrant materials from it [1]. Now a days the nature of drinking water is major task because of increasing pollution in water bodies [2]. Fluoride is a to harmful, electronegative, most reactive, inorganic \& nonmetallic substance which gave negative impact on human health when we take extra amount above standard level. Fluorine is yellow colour gas with corrosive properties and strong oxidative capacity and strong odor [3]. We consume fluoride through water, air, drugs, food and various cosmetic products [4]. Fluoride is pollutant that dangerous for living life forms, specifically people [5]. For 
mineralization of bone and teeth and assurance towards dental reasons the little amount of fluoride is very vital. Higher consumption of fluoride caries decay of teeth enmel called fluorosis. In tropical nations like India, Kenya, Tanzania \& Senegal, the issue of fluoride in water bodies is very serious [6]. Fluoride is beneficial to young children when present in limited amount of 1.0 to $1.5 \mathrm{mg} \mathrm{F} /$ litre. The fluoride occurs as fluorapatite, cryolite, fluorspar \& sellaite. In sedimentary rock as a fluorspar and in igneous rocks as a cryolite. By weathering of fluoride rich minerals and by anthropogenic action fluoride is enters in aqueous environment [7]. According to World Health Organization (WHO) maximum contamination level of fluoride in drinking water is $<1.5 \mathrm{mg} / \mathrm{L}$. In natural water bodies fluoride levels up to $2800 \mathrm{mg} / \mathrm{L}$ believed to emanate from natural rock or anthropogenic sources like waste water from industry from metallurgical and alluminium manufactures, semiconductors, ceramics, phosphate fertilizer, electronics and glass industry $[8,9]$. Highest fluoride concentration contains from all of water sources is groundwater range from 1.0 $\mathrm{mg} / \mathrm{L}$ to $35.0 \mathrm{mg} / \mathrm{L}$ depends on physical and chemical behavior of aquifer and it's reaction with surrounding [10]. The best way to get rid from this issue is defluoridation. For the removal of fluoride, various techniques are there. For example, precipitation-coagulation, ion-exchange, membrane based process like forward and reverse osmosis and adsorption process. The precipitation-coagulation method includes leaching of unwanted compounds made large amount of sludge. Procedure through membrane is fouling and lavish as inescapable problem. Minimized water disposal and ease by adsorption procedure [11]. National environmental engineering research institute (NEERI), Nagpur, India, develop a method known as Nalgonda technique [12], involves addition in sequences of an alkali, chlorine \& aluminium sulfate or aluminium chloride. It is extensively used and very cheap in India. Materials likes activated carbon, activated alumina, ion-exchange resin\& bone char are used in adsorption technique [13]. This technique is dependent highly on $\mathrm{pH}$ and effective at less than $3.0 \mathrm{pH}$ and little removal at neutral $\mathrm{pH}$ value of 7.0. [14-16]. Low cost materials like serpentine are effective in fluoride removal ranging from $6.5 \mathrm{mg}$ to $\mathrm{F} /$ litre to $1.0 \mathrm{mg} \mathrm{F} /$ litre [17]. Charfinesare by product we got during obtain coke from lignite coal. Nirmali seeds are used for remove pollutants like color etc. from water. Each techniques has advantages and disadvantages and comparisons, differences and conceptual overviews have been conducted. 
2. Fluoride removal from water by various method

To overcome the risky welfare impact of fluorosis, distinct perspective for fluoride removal is there example like coagulationprecipitation, ion-exchange, membrane separation, adsorption etc. Each method work effectively and productively under suitable and ideal condition for defluorodation to noteworthy range [11].

\subsection{Precipitation and coagulation technique}

Many coagulants utilized for Nalgonda method for removal of fluoride from water. Example is lime and alum which is mostly used. Lime extension give rise to the fluoride precipitation as insoluble calcium fluoride and increases the $\mathrm{pH}$ range upto 11 to 12 . As we seen the lime leave a leftover of $8.0 \mathrm{mg} \mathrm{F} / \mathrm{I}$, which continually attach with alum for fluoride removal. In a first step due to lime dosing precipitation occur. Which drag by second step in which alum is put on to bring about coagulation. At that time when we add alum into the water, two reactions occur. In initial reaction, with an alkalinity's portion an alum is reacted to produce insoluble aluminiumhydroxide $\left[\mathrm{Al}(\mathrm{OH})_{3}\right]$. In the second reaction, fluoride ion is react with alum in the water. Accomplishment of best fluoride removal happen at $\mathrm{pH}$ of $5.5-7.5$ [18]. An expansion of aluminium salt, lime and bleaching powder took after by flocculation, sedimentation, quick mixing and filtration in a coagulation-precipitation method of Nalgonda techniques created by NEERI. For removal of fluoride from water aluminium salt is used. Dosage of fluoride is depended on the fluoride concentration proportionally. Lime dosage is $1 / 20^{\text {th }}$ of alum dosage. For fast settling lime distribute bigger shape and denser flocs. For cleansing purpose, bleaching powder is added at the rate of $3 \mathrm{mg} / \mathrm{l}$ [19]. At community level this is the most generally used method for fluoride removal [20, 21]. For household utilize, the bucket defluoridation system based Nalgonda method developed [22]. The process is worthy for 20 litres water for one day consumption. Around 1 to $1.5 \mathrm{mg} / 1$ leftover fluoride in water is proceed by this process [23], We also use fill and draw type fluoride removal technique based on Nalgonda technique [22]. In account of coprecipitation technique for aluminium salts have interested and restricted points mention below:-

- Interest

1. Most generally used technique.

2. More worthy and practical method when compare with other fluoride removal technique.

3. Very easy and simple technology to understand.

- Restriction 
1. Chemical dosage requirement are very high $\left[\mathrm{Al}(\mathrm{OH})_{3}\right.$ range from $\left.700-1200 \mathrm{mg} / \mathrm{l}\right]$.

2. Issue of slurry move.

3. Requirement of talented labor.

4. Highly chances of Alzheimer's syndrome due to aluminium release in treated water.

5. Dissolvability of fluoride, calcium \& aluminium salt precipitation effect on final concentration of fluoride in treated water. 6. Use of aluminium sulfate as coagulant increase concentration of sulfate ion which promote highly chances of catharatic impact on health of human health.

A contact precipitation defluoridation technique use bone char along with calcium chloride and sodium dihydrogen phosphate [23]. The combine use of calcium salt and polymeric aluminium hydroxide for fluoride removal is succeed contemplated by Narthasarthy et al. Chang and liu examined flocculation -coagulation technique of calcium fluoride precipitates in addition with polyacrylic acid \& polyaluminium chloride at low dosage. granular calcite is used to catch fluoride present in water as calcium fluoride in fluidized bed reactor for beat the restriction of chemical precipitation by Aldaco et al. [24].

\subsection{Reverse osmosis (RS) and nanofiltration membrane technique for defluoridation [pressure]}

To obtain high quality water from saline and waste water sources, reverse osmosis and nanofiltration are best membrane technologies which have a many basic similarities. reverse osmosis or nano filtration which technique is utilize by a membrane is highly depends on the process in which membrane is used [25]. Nano filtration membranes are habitually use when deflect osmotic pressure is need, whereas by using semi permeable membrane for separation of solutes $\mathrm{RO}$ use the osmotic pressure [26]. Low pressure and less energy needed by nanofiltration membranes which show faster flow because they have larger pores than RO membranes and show less rejection.in seawater \&brackish water reverse osmosis is frequently used. In industrial waste water treatment NF is mainly used which use thin-film composite polyamide membranes [27]. For desalination process, RO is the cost-effective \& most energy-efficient method,with a minimum energy of 1.06 $\mathrm{kWh} / \mathrm{m} 3$ \& energy cost of approximately $1.8 \mathrm{kWh} / \mathrm{m} 3$ at $50 \%$ recovery $[28,29]$. Various separation mechanisms like size exclusion, chargerepulsion, solution diffusion, and adsorption utilize by NF/RO membrane so the highest rejection of solutes can be achieved by them, the higher the probability of rejecting solutes directly proportional to the larger the number of separation techniques with various chemical characteristic for complete removal of inorganics [30-32] and organics [33-35] use of NF/RO has been prove at 
field scales \& laboratory since it's invention, this processes is mostly use for removal of fluoride from polluted water [36-38].

Between RO and ultrafiltration, nanofiltration have many properties require lower energy, pressure \& low investment, maintenence cost and operation have a higher permeate flux \& retention of charged matter.

\subsection{Rejection mechanisms}

On pressure gradients \& interactions between contaminants and membrane materials the mechanism of solute retention of $\mathrm{RO} / \mathrm{NF}$ membrane is depends. Combination of the rejection mechanism attribute of porous and non porous membrane is simply a NF membrane operation and transport. Through diffusion, convection and electromigration, the fluoride ions in the $\mathrm{NF} / \mathrm{RO}$ membrane method on the permeate side are migrate. By amalgamation of size exclusion, charge exclusion, and adsorption rejection methods solute rejection can be accomplish which can be control by physiological interactions between solvent, solute and membrane [39]. Due to charge and steric effect, selectivity in NF happen. Because of steric effect due to higher hydration energy and higher charge density, the fluoride rejection in NF occur. More quick hydration and retention of fluoride on NF membrane than else monovalent anions because of favour of this effect [40].

\subsection{RO/NF factors affecting fluoride removal}

Feed water characteristics, membrane properties \&operational conditions are 3 major factor which rule the flux, selectivity, recovery and overall economics of $\mathrm{NF} / \mathrm{RO}$ membranes.

\subsubsection{Feed water composition}

Three major ways are there for fluorie removal by feed Firstly, by the complexity of water matrices, presence of inorganic and organic pollutants with different concentration and behavior \& interactions with fluoride ions and membrane rejection is obstruct. By water matrices, removal of pollutants is not affected but fluoride removal is affected either positively or negatively. Natural organic matter effect on fluoride removal because of it's action of zeta potential of membrane due to adsorption of organic matter \& increasing the negative surface charge.

Secondly, removal efficiency is affected by the presence of other anions like nitrates, bicarbonate, sulfate and chloride. On coexisting anions, NF has a retention effect. Owing the availability of other anions by positive result of anion size influence and hydration energy on fluoride removal. Organization of removal process is decreases by chloride ions in solution. Because of increase in ionic strength, at 
higher sulfate concentration reduction of fluoride ion rejection happens. Which decrease hydration energy and increases partition coefficient which is in charge for membrane selectivity.

Thirdly, an enlarge of the ionic strength by increase in water matrices which stipulation the enhancement of fluoride permeation and application use of higher operating pressure. Owusu-Agyeman et al. 2019 and Wang and Li 2009 suggested that with an expansion of influent salt concentration, the decreases in removal of fluoride by $\mathrm{RO} / \mathrm{NF}$.

\subsubsection{Operational conditions}

The most important parameters which influence selectivity of fluoride is the operational condition of $\mathrm{RO} / \mathrm{NF}$ systems. Feed water $\mathrm{pH}$, pressure, temperature, regular maintenance, monitoring, initial fluoride concentration (IFC),operating time, target recovery, target standard and cross flow rate are the numerous operationally important factors which should be considered at the time of design and operation of $\mathrm{RO} / \mathrm{NF}$ plants.

\subsubsection{Effect of $\mathrm{pH}$}

The $\mathrm{pH}$ of solution is very important operating parameter that act on hydration of solute, charge, size and zeta potential and pore size of membrane, which affect selectivity and flux of entire process [38]. In a weak alkaline environment, operating of fluoride removal by $\mathrm{RO} / \mathrm{NF}$ membrane occur [44] because of increase in negative surface charge for polymeric membrane when feed water $\mathrm{pH}$ is increase. Most NF membranes have a negatively charged functional group so the presence of solutes species in the negatively charged favors the rejection of fluoride. At $\mathrm{pH}$ typically $<$ 3.0 low $\mathrm{pH}$, repulsion is minimal due to fluoride in the neutral free hydrofluoric acid (HF) from diffuses through membranes. The decrease in the viscosity of feed solution by the increasing the $\mathrm{pH}$ and hence, flux is affected subsequently by reduce the concentration polarization [36] Membrane reveal decrease fluoride rejection in strong alkaline condition. Because of $\mathrm{F}-$ and $\mathrm{CO} 32-$ interactions, synergistic effects of higher salt concentration and $\mathrm{pH}$, and charge concentration polarization.

\subsubsection{Effect of pressure}

Operating pressure is another necessary parameter in RO/NF which influences property and flux. The substance moving and permeate water quality decay in NF is also a results of view which can be a purpose of solubilization or diffusion and transfer Hence, the convection transfer component is influence by changing physical parameters such as pressure. Chemical variable like feed water $\mathrm{pH}$ is affect on the diffusion component. Only chemical parameters are take part in $\mathrm{RO}$ 
processes. The lower pressure-operated diffusion component in which chemical selectivity due to the solvation energy of ions through water predominates, most of selectivity of fluoride likes very smaller ions. The solute driving force is only marginally influence by increasing in operating pressure, But affects the NF flux greatly. It also affect on RO flux but less than the NF.14 $\mathrm{keg} / \mathrm{cm} 2$ is an best operating pressure and increase in pressure did not considerable consequence on rejection of fluoride. Through the osmotic potential of the feed solution, the optimal or maximum operating pressure in $\mathrm{RO}$ is determined. Increase in flux and rejection rates is equally proportional to increasing in the operating pressure in the RO process. For the RO process the operating pressure for fluoride removal is suggest to be above 0.2 MMp. Expansion in the operating pressure is affect on $\mathrm{pH}$ by deceases the permeate $\mathrm{pH}$, as alkaline ion are reject by NF membrane [36].

\subsubsection{Effect of temperature}

During the flux and fluoride rejection in $\mathrm{RO} / \mathrm{NF}$ membrane temperature also has a impacts either positive or negative on Because of osmotic pressure enhancement elevated temperature suppresses flux production by membrane. Viscosity is also decreases by temperature conversely which favour lower energy requirement. Arora et al. (2004) suggest that an ideal temperature of 30.C for removal of fluoride through RO membranes, due to solute solubility and diffusion coefficients fluoride selectivity will be considerably influence. However, the arsenic rejection rate does not affected by the temperature.

\subsubsection{Initial fluoride concentration}

The only water that treated by $\mathrm{RO} / \mathrm{NF}$ membrane is a water that containing IFCs up to a certain critical limit. Optimum IFC depends on standard which targeted, the drinking standard of WHO is $1,5 \mathrm{mg} / \mathrm{L}$. And the standard of the environmental effluent disposal is approximately $15 \mathrm{mg} / \mathrm{L}$. The use of NF membranes is limited to elevated feed fluoride levels. So, NF membranes and low pressure RO membranes can give enough and economical option for treating fluoride in water providing the IFC is low. At same time, similar to the rejection rate if IFC is high than the flux will also be affected.

\subsubsection{Effect of recovery}

Recovery is also important parameter which affects flux and fluoride retention. It is assumed that increasing the require recovery value will decease selectivity because of the increase in the fluoride ion diffusion rate resulting from concentration polarization near the membrane surface. The NF membrane is more sensitive to recovery rate than $\mathrm{RO}$ membrane [38]. This is allocated to the higher permeability facilitates and diffusion rates of fluoride in 
NF membranes and due to effect on RO membranes is limited as size exclusion is important rejection mechanism.

\subsubsection{Operational time}

Flux and selectivity is also affected by the operational time. On the time increases, the concentration polarization near membrane surface also increases, which influence fluoride diffusion by the membrane. The fluoride removal of $\mathrm{RO}$ remains stable and NF increases with increases operation time.

\subsubsection{Membrane type}

The selection of an appropriate membrane is most difficult step in design and operation of RO/NF membrane. For match contaminant behavior and water qualities, a membrane type is typically selected. The performance of RO/NF membrane depends on feed $\mathrm{pH}$, required flux, recovery rate, IFC in the feed water $\&$ targeted treatment standard. So the physical and chemical behavior of fluoride ion and membrane should be characterized. The membrane must be well harmonized with fluoride rejection mechanism. The useful membrane characteristics is molecular weight/molecular weight cut-off (MWCO), acid dissociation constant (Pka), hydrophobicity or hydrophilicity (constant angle), diffusion coefficient, pore size, surface charge, surface charge density (ZETA POTENTIAL) and membrane morphology. Believe to the existence of steric effect, RO/NF membrane which have lower MWCO values can reject fluoride effectively. Fluoride is very small ion with an ionice radius which is $0.13 \mathrm{~nm}$, its size actually increase after hydration, favours size exclusion by NF membranes [38].

\section{Fluoride removal by adsorption} technique

Adsorption is that the bond of molecules species from bulk solution for a surface of a solid by chemical or physical forces. Surface assimilation procedures embrace the water's entry through a contact bed wherever halide is removed by particle exchange or surface reaction with the solid bed matrix. As distinction with completely different procedures of defluoridation, Surface assimilation technique is distinguished owing to its straightforwardness and additionally accessibility of in depth variety of adsorbents. Surface assimilation onto solid surface is straightforward, versatile and appropriate procedure for treating water systems, significantly for little groups. Surface assimilation technique is economical and may take away ions over an in depth style of $\mathrm{pH}$ scale to a lower leftover concentration than precipitation. Many adsorbent materials are tried within the past to see their possibilities and techno-economic feasibleness as defluoridating specialists. Activated aluminum oxide, activated carbon, activated aluminum oxide coated colloid, calcite, activated saw mud, activated 
coconut shell powder, activated ash, groundnut shell, occasional husk, rice husk, magnesia, serpentine, tri-calcium phosphate, bone charcoal, activated soil sorbent material, defluoron-1, defluoron-2 and so on varied adsorbent materials rumored in literature. The foremost frequently used adsorbents square measure activated aluminum oxide and atomic number 6 . The halide removing potency of activated aluminum oxide gets influenced by hardness, $\mathrm{pH}$ scale and surface loading (the magnitude relation of total fluoride concentration to activated aluminum oxide dosage). The adsorption procedure will take away halide up to ninetieth and the treatment is exceptionally sensible. Regeneration is needed once at regular intervals of 4-5 months and viability of adsorbent for halide removal reduces once every regeneration cycle. McKee and J. E. Johnston investigated the employment of fine-grained atomic number 6 for halide removal and accomplished noble outcomes.

The procedure is $\mathrm{pH}$ scale dependent with noble results just at $\mathrm{pH}$ scale three. 0 or less. Hence, the employment of this material is costly owing to want of $\mathrm{pH}$ scale alteration. Activated alumina technique for defluoridation is being proliferated in some villages by the organizations funded by UNICEF or completely different agencies to grant safe water. Sarita Sansthan, Udaypur, Rajasthan is spreading the method with the viable facilitate of United Nations International Children's Emergency Fund by giving a bucket (approximately twenty L capacity) fitted with a micro filter at rock bottom containing five kilo of activated alumina.

\section{Future Perspective}

This survey proposes the accompanying potential further examination that is appropriate to the use of layer innovation for defluoridation.

- Sustainability examination of different cycles utilizing progressed apparatuses for example, life cycle appraisal (LCA) are of most extreme significance and ought to be explored.

- More information actually needed at modern scale to guarantee its appropriateness in bitter groundwater and wastewater treatment.

- An extensive audit and correlation tending to the defluoridation ability of the regular and layer measures from financial, specialized, and ecological perspectives are required.

- Membrane conduct influences defluoridation execution. An experiment with a target to profit, manufacture, or coat a particular film for the defluoridation reason ought to be given due attention.

- Hybridizing distinctive defluoridation systems (among both layer measures and ordinary strategies) is firmly exhorted, to 
exploit the valuable ascribes of every technique.

- Further survey and itemized exploratory investigations are needed to arrive at any decisions about the application and monetary feasibility of FO frameworks for fluoride evacuation.

- The utilization of defluoridation methods has been concentrated more for regular groundwater and harsh water sources than for wastewater. In this manner, further examinations are needed to notice the performance of various layer measures in treating exceptionally fluoridated modern wastewaters.

- Now withstanding investigations of the relative defluoridation execution of all the layer measures, further issues identified with plan considerations ought to be inspected corresponding to water quality, framework parts, site contemplations, leftover administration and removal, upkeep, checking, and operational intricacies, just as different improvement and alteration issues. Ends this basic survey sums up the distinctive accessible layer.

\section{CONCLUSION}

This review has endeavored to hide an in depth selection of procedures that are used up to now for the removal of halide from the potable and industrial wastewater. The standard system of removing halide from potable is liming and also the attending precipitation of halide. Then again, the weaknesses of the overwhelming majority of those ways area unit high operational and upkeep prices, auxiliary contamination, as an example, generation of toxicant sludge so on and intricate method included within the treatment. Distinctive technologies systems, utilized for defluoridation, were discriminatingly examined. It absolutely was reasoned that action ways have by and huge been discovered compelling in defluoridation, however they're unsuccessful in transference halide to fancied concentration levels. The search for choice and appropriate halide removal ways thus still stays of curiosity.

\section{REFERENCES}

[1] Bao T, Damtie MM, Wu K, Wei XL, Zhang Y, Chen J, Deng CX, Jin J, Yu ZM, Wang L, Frost RL. Rectoritesupported nano-Fe3O4 composite materials as catalyst for P-chlorophenol degradation: Preparation, characterization, and mechanism. Applied Clay Science. 2019 Aug 1; 176: 66-77.

[2] Waghmare SS, Arfin T. Fluoride removal from water by calcium materials: a state-of-the-art review. International Journal of Innovative Research in Science, Engineering and Technology. 2015 Sep; 4(9): 8090-102

[3] Majewska-Nowak K, Grzegorzek M, Kabsch-Korbutowicz MA. Removal of fluoride ions by batch electrodialysis. Environment Protection Engineering. 2015; 41(1). 
[4] Meenakshi GV, Kavita R, Malik A. Groundwater quality in some villages of Haryana, India: focus on fluoride and fluorosis. J Hazard Mater. 2004 Jan 2; 106(1): 55-60.

[5] Waghmare SS, Arfin T, Manwar N, Lataye DH, Labhsetwar N, Rayalu S. Preparation and characterization of polyalthialongifolia based alumina as a novel adsorbent for removing fluoride from drinking water. Asian J. Adv. Basic Sci. 2015 Aug 20;4(1):12-24.

[6] Waghmare SS, Arfin T. Fluoride removal from water by mixed metal oxide adsorbent materials: a state-ofthe-art review.

[7] Mohapatra M, Anand S, Mishra BK, Giles DE, Singh P. Review of fluoride removal from drinking water.

[8] Min BR, Gill AL, Gill WN. A note on fluoride removal by reverse osmosis. Desalination. 1984 Jan 1; 49(1): 89-93.

[9] Ndiaye PI, Moulin P, Dominguez L, Millet JC, Charbit F. Removal of fluoride from electronic industrial effluentby RO membrane separation. Desalination. 2005 Mar 1; 173(1): 2532.

[10] Keri RS, Hosamani KM, Reddy HR, Nataraj SK, Aminabhavi TM. Application of the electrodialytic pilot plant for fluoride removal. Journal of Water Chemistry and Technology. 2011 Oct; 33(5): 293-300.

[11] Waghmare SS, Arfin T. Fluoride removal from water by various techniques. Int $\mathrm{J}$ InnovSciEng Technol. 2015; 2(9): 560-71.

[12] Bulusu KR, KR B, BB S, WG N. Fluorides in water, defluoridation methods and their limitations.

[13] Mckee RH. Removal of flourides from drinking water. Industrial \& Engineering Chemistry. 1934 Aug 1; 26(8): 849-51.

[14] Boruff CS. Removal of fluorides from drinking waters. Industrial \& Engineering Chemistry. 1934 Jan 1; 26(1): 69-71.

[15] Fink GJ, Lindsay FK. Activated alumina for removing fluorides from drinking water. Industrial \& Engineering Chemistry. 1936 Aug; 28(8): 947-8.

[16] Swope HG, Hess RH. Removal of fluorides from natural waters by defluorite. Industrial \& Engineering Chemistry. 1937 Apr; 29(4): 424-7.

[17] Kulkarni DN, Nawlakhe GW. Serpentine-Its limitations as a defluoridation medium. Indian $\mathrm{J}$. Environmental Health. 1974; 16: 151.

[18] Razbe N, Razbe N. Various options for removal of fluoride from drinking water. IOSR Journal of Applied Physics. 2013; 3: 40-7.

[19] Admashri JP. Effectiveness of low cost domestic defluoridation. In International Workshop on Fluoridation Water Strategies, Management and Investigation, Bhopal 2001 (pp. 27-35). 
[20] Nawlakhe WG, Rao AV. Evaluation of defluoridation plant at Tartatur. Journal of Indian Water Works Ass. 1990; 13: 287-90.

[21] Nawlakhe WG, WG N, KR B. Defluoridation of water by Nalgonda technique.

[22] Mjengera $\mathrm{H}$, Mkongo G. Appropriate technology for use in fluoritic areas in Tanzania, 3rd Waternet. In WARFSA Symposium on water demand management for sustainable use of water resources, University of Dar Es Salaam 2002.

[23] Dahi E. Contact precipitation for defluoridation of water [Discussion paper]. In Reaching the unreachedChallenges for the $21^{\text {st }}$ century: Proceedings of the 22nd WEDC International Conference, New Delhi, India 1996 Sep (pp. 262265). cc WEDC, Loughborough University.

[24] Adhikary SK, Tipnis UK, Harkare WP, Govindan KP. Defluoridation during desalination of brackish water by electrodialysis. Desalination. 1989 Jan 1; 71(3): 301-12.

[25] Paul M, Jons SD. Chemistry and fabrication of polymeric nanofiltration membranes: A review. Polymer. 2016 Oct 26; 103: 417-56.

[26] Al-Obaidi MA, Kara-Zaitri C, Mujtaba IM. Scope and limitations of the irreversible thermodynamics and the solution diffusion models for the separation of binary and multi-component systems in reverse osmosis process. Computers \& Chemical Engineering. 2017 May 8; 100: 48-79.

[27] Lutskiy MY, Avneri-Katz S, Zhu N, Itsko M, Ronen Z, Arnusch CJ, Kasher R. A microbiology-based assay for quantification of bacterial early stage biofilm formation on reverse-osmosis and nanofiltration membranes. Separation and Purification Technology. 2015 Feb 12; 141: 214-20.

[28] WA EM. The future of seawater desalination: Energy, technology, and the environment Science 333712. Elimelech, M., and Phillip, WA (2011). The future of seawater desalination: Energy, technology, and the environment. Science. 2011; 333: 712 .

[29] Jiang S, Li Y, Ladewig BP. A review of reverse osmosis membrane fouling and control strategies. Science of the Total Environment. 2017 Oct 1; 595: 56783.

[30] $\mathrm{Hu} \mathrm{J,} \mathrm{Pu} \mathrm{Y,} \mathrm{Ueda} \mathrm{M,} \mathrm{Zhang} \mathrm{X,}$ Wang L. Charge-aggregate induced (CAI) reverse osmosis membrane for seawater desalination and boron removal. Journal of Membrane Science. 2016 Dec 15; 520: 1-7.

[31] Schmidt SA, Gukelberger E, Hermann M, Fiedler F, Großmann 
B, Hoinkis J, Ghosh A, Chatterjee

D, Bundschuh J. Pilot study on arsenic removal from groundwater using a small-scale reverse osmosis system-Towards sustainable drinking water production. Journal of hazardous materials. 2016 Nov 15; 318: 671-8.

[32] Yang Y. Beyond the conventional "life cycle" assessment. Biofuel Research Journal. 2017 Jul 1; 4(3): 637.

[33] Bao T, Jin J, Damtie MM, Wu K, Yu ZM, Wang L, Chen J, Zhang Y, Frost RL. Green synthesis and application of nanoscale zero-valent iron/rectorite composite material for P-chlorophenol degradation via heterogeneous Fenton reaction. Journal of Saudi Chemical Society. 2019 Nov 1; 23(7): 864-78.

[34] Shanmuganathan S, Loganathan P, Kazner C, Johir MA, Vigneswaran S. Submerged membrane filtration adsorption hybrid system for the removal of organic micropollutants from a water reclamation plant reverse osmosis concentrate. Desalination. 2017 Jan 2; 401: 13441.

[35] Verliefde AR, Cornelissen ER, Heijman SG, Verberk JQ, Amy GL, Van der Bruggen B, Van Dijk JC. The role of electrostatic interactions on the rejection of organic solutes in aqueous solutions with nanofiltration. Journal of Membrane Science. 2008 Sep 1; 322(1): 52-66.

[36] Chakrabortty S, Roy M, Pal P. Removal of fluoride from contaminated groundwater by cross flow nanofiltration: transport modeling and economic evaluation. Desalination. 2013 Mar 15; 313: 115-24.

[37] Richards LA, Richards BS, Rossiter HM, Schäfer AI. Impact of speciation on fluoride, arsenic and magnesium retention by nanofiltration/reverse osmosis in remote Australian communities. Desalination. 2009 Nov 15; 248(13): 177-83.

[38] Richards LA, Vuachère $M$, Schäfer AI. Impact of $\mathrm{pH}$ on the removal of fluoride, nitrate and boron by nanofiltration/reverse osmosis. Desalination. 2010 Oct 31; 261(3): 331-7.

[39] Shen J, Schäfer A. Removal of fluoride and uranium by nanofiltration and reverse osmosis: a review. Chemosphere. 2014 Dec 1; 117:679-91.

[40] Mohapatra M, Anand S, Mishra BK, Giles DE, Singh P. Review of fluoride removal from drinking water. Journal of environmental management. 2009 Oct 1; 91(1): 67-77. 